\title{
The Challenges of Quality Assurance and Accreditation in Afghanistan: A Policy Implementation Analysis
}

\author{
Sayed Ahmad Javid Mussawy
}

University of Massachusetts Amherst

Email: smussawy@umass.edu

Address: 809 North Pleasant Street, Amherst, MA 01003

\section{Introduction}

The quest for quality has evolved as a major concern for higher education institutions (HEIs) in developing world. A majority of these countries have adopted quality assurance and accreditation (QAA) policies in order to improve the quality of higher education services. However, implementation of QAA has generated diverse responses among different types of HEIs as their mission and scope of work vary from one another. For instance, in Afghanistan, public universities emphasize more on curriculum alignment with labor market, student centered instruction, and faculty capacity building, while private HEIs focus on mechanisms to regulate student admissions, long-term faculty employment, and partnership development (MoHE 2018; Hayward 2015). Although public HEIs in Afghanistan are fully funded by the government (McNernery 2009), they are concerned about lack of autonomy and inadequate infrastructure to fulfill accreditation standards (Roof 2018; Berger and Thoma 2015). As a result, implementing a QAA in public HEIs is not a linear process. The current research examines the challenges faced by public universities in Afghanistan as they implement a QAA system. More specifically, the study investigates how sensemaking and sensegiving occur as QAA is implemented at teaching versus research universities, and ways in which key-informants at various institutions make use of sensemaking and sensegiving as a tool to interpret the policy. The higher education system in Afghanistan has experienced fluctuation due to political uncertainties in the past four decades. The student enrollment numbers were 24,333 in 1990 even though the country was under the invasion of the Soviet Union. However, the political unrest a decade of 1992-2001 caused by the civil conflicts involving the Mujahedeen in 1992, and the Taliban in 1996, severely damaged higher education sector, which resulted in only having 6,600 students enrolled in the existing 12 HEIs (Babury and Hayward 2014). The Taliban era was particularly devastating as females were banned from any form of education (Hayward and Karim, 2019). However, beginning in 2002 with a change in political regime and direct involvement of the United States, the higher education has experienced an explosive expansion (Ibrahimi 2014; Roof 2018). A rapid growth of higher education sector as well as a mismatch between different HEIs services - failing to train graduates with relevant competencies - and the expectations of the labormarket have caused global concern about quality (Altbach and Knight 2007; Williams 2016). The concern for quality is particularly significant in higher education systems in developing countries (Kapur and Crowley 2008). The system expansion in Afghanistan was very rapid. In 2008, the existing 29 HEIs enrolled 58,769 students; however, within a decade, in 2018, the number of HEIs increased to 169 serving 388,191 students (MoHE 2018; Mussawy and Rossman 2018). In response to the rapid growth, the Ministry of Higher Education partnered with the USAID, the World Bank, and the British Council to establish a QAA process as a mechanism to improve quality (Aturupane, Sofizada and Shojo 2013; Chase-Mayoral and Amiri 2018; Roof 2014). Nevertheless, only research universities were able to meet the QAA benchmarks and to achieve national accreditation in the past three years, while the majority of teaching 
universities experienced great difficulties. In fact, the QAA policy seems to be discriminating against teaching universities as they lack both adequate infrastructure and resources to meet the accreditation benchmarks.

The existing literature on QAA contends that accreditation functions as a fence to protect institutional identity against external environment (Blanco-Ramírez and Berger 2014; Skolnik 2010). The literature on QAA shows two major trends. One perspective is the criticism towards the use of corporate-driven quality assurance models as the measure to assess the quality of higher education services and to question whether quantification of higher education services produces a true measure of quality standards (Srikanthan and Dalrymple 2007). The other emphasizes QAA outcomes, illuminating how QAA efforts contribute to quality improvement and increase accountability. What is missing in the literature is how implementing QAA policies affect different types of HEIs, and the challenges faced by teaching-centered universities when implementing a "one-size-fits-all" approach to accreditation.

\section{Theoretical Framework}

The research uses sensemaking and sensegiving (Weick 1995) as a theoretical lens to analyze and interpret the implementation of accreditation at public HEIs in Afghanistan. Sensemaking is defined as a dynamic and exploratory process of learning, understanding, developing meaning, and identifying patterns (Gioia and Chittipeddi 1991; Kezar 2013; Weick 1995). While some authors use the terms sensemaking and sensegiving interchangeably, Gioia and Chittipeddi (1991) make distinguish them as two independent process by stating that sensemaking refers to a process of "meaning construction and reconstruction by the involved parties", and sensegiving denotes a "process of attempting to influence the sensemaking and meaning construction of others" (p. 442). Similarly, Weick, Sutcliffe, and Obstfeld (2005) assert "sensemaking unfolds as a sequence in which people concerned with identity in the social context of other actors engage ongoing circumstances from which they extract cues and make plausible sense retrospectively, while enacting more or less order into those ongoing circumstances" (p. 409). Others interpret sensemaking as a collaborative learning process (Maitlis and Lawrence 2007), an interpretive exercise (Kezar 2013), and an ongoing exploration of organizational events (Gioia and Thomas 1996). Given these conceptualizations, sensemaking and sensegiving may well serve two purposes: (a) gathering information from multiple sources to learn what is going on, and (b) scrutinizing how others (organizational members) should interpret the information (Maitlis and Lawrence 2007).

Weick's (1995) "sensemaking" is the best framework for studying QAA in higher education system in Afghanistan because adopting QAA triggers disruption at universities. Stakeholders are expected to interpret the policy, make priorities, redefine roles and responsibilities and engage in constructive conversations and activities, in order to uphold the identity of their respected institutions and exhibit an image that builds trust in the public. The author views implementing accreditation, or any policy, as an instance of organizational change and thus relevant to sensegiving and sensemaking. Implementing accreditation affects institutional culture within universities as it is assumed to alter faculty and staff assumptions about ongoing events (Stensaker 2007). Weick (1995) and Gioio and Chittipeddi (1991) established sensemaking/sensegiving as an analytical approach to examine how meanings are constructed among organization leaders and followers, and how they shape or inspire one another's interpretation. While previous research found sensemaking useful tool to study higher education in Western contexts such as the US and Europe (Degn 2015; Kezar 2013; Gioio and Chittipeddi 1991), the present research examines ways that sensemaking framework can contribute to a better understanding of QAA challenges in a non-Western context, such as Afghanistan.

\section{Method}


The research seeks to answer the following questions: (1) How does sense-making/giving occur as teaching and research universities respond to QAA policy? And (2) What are the experiences of stakeholders at public universities in relation to QAA? The investigator used a qualitative multi-case study approach (Rossman and Rallis 2016) to collect data from a total of 46 participants that included 31 individual interviews and three focus group. The research took place at two research universities, three teaching-centered universities, the national quality assurance and accreditation agency, and three donor agencies. Research participants included senior officials at QAA directorate, senior university administrators, internal quality assurance units, peer-reviewers, and donor representatives. The investigator used a combination of participant observation, archival review, and semi-structured interviews to triangulate the data.

\section{Preliminary Results}

This research is currently in the data analysis phase. The research uses two levels of analysis to make sense of the data: (1) Marshall and Rossman's (2016) generic steps for qualitative data analysis help in analyzing each case independently; (2) Creswell's (2014) multiple-case study design assists in developing "a detailed description of the setting, followed by analysis of data for themes or issues" (p. 267). The study intends to contribute to policy development and policy analysis literature. It highlights the role of contextual factors in policy formulation, and challenges a standard, "one-size-fits-all” approach to implementing higher education policies.

Preliminary findings suggest that administrative protocols overshadow the goals of implementing QAA at public universities. The results highlight the significance of senior administrators' involvement in interpreting the accreditation framework (sensemaking) and making strategic decisions (sensegiving) to overcome accreditation goals. Universities, where the leadership team was actively involved in translating accreditation standards into manageable functions (sensemaking/giving), made greater progress in comparison to those with minimal engagement of the leadership team.

In teaching-centered universities, although the lack of adequate resources and institutional autonomy were highlighted as the main factors that inhibited a successful implementation of QAA, the results suggest that absence of a guided sensemaking and sensegiving (Gioio and Chittipeddi 1991) approach was the primary factor that resulted in information gaps and lack of engagement among faculty and staff in QAA processes. Findings also suggest that sensemaking was minimal at teaching-centered universities as they experienced great difficulty in developing mechanisms to unpack various aspects of QAA policy. More specifically, QAA related tasks were delegated to subordinates prior to a deeper understanding of the policy at the leadership level. In other words, research highlighted a lack of alignment between senior executives' interpretation of policy and functions that were chosen to address the problem. The study documents that participants have a positive view about QAA as a national system to oversee quality of higher education services. However, the research highlights that teaching-centered HEIs lack the structures and systems needed to effectively internalize a foreign-derived QAA policy. As a result, implementing accreditation as the sole mechanism to improve quality remains a contested process.

\section{References}

Altbach, Philip G., and Jane Knight. 2007. "The Internationalization of Higher Education: Motivations and Realities." Journal of Studies in International Education 11(3-4): 290-305. https://doi.org/10.1177\%2F1028315307303542. Aturupane, Harsha, Abdul Hai Sofizada, and M. Shojo. 2013. Higher Education in Afghanistan: An Emerging Mountainscape. Washington, DC: The World Bank. 
Babury, Mohammad Osman and Fred M. Hayward. 2014. "Afghanistan Higher Education: The struggle for quality, merit, and transformation." Planning for Higher Education 42(2): 1-32.

Berger, Joseph B., and Hanni S. Thoma. 2015. "The Challenges of Developing an Autonomous Higher Education System in Afghanistan". International Higher Education 81: 20-21. https://doi.org/10.6017/ihe.2015.81.8738.

Blanco-Ramírez, Gerardo, and Joseph B. Berger. 2014. "Rankings, Accreditation, and the International Quest for Quality: Organizing an Approach to Value in Higher Education." Quality Assurance in Education 22(1): 88-104. https://doi.org/10.1108/QAE-07-2013-0031.

Chase-Mayoral, Audree, and Fayaz Amiri. 2018. "Economics of Education in Afghanistan: Expanding Academic Programs Based on Market Demands Dictated by International Agency Funds Toward Self-Sustainability." In Handbook of Comparative Studies on Community Colleges and Global Counterparts, edited by Rosalind Latiner Raby and Edward J. Valeau, 113-130. Netherland: Springer International Publishing.

Creswell, John W. 2014. A Concise Introduction to Mixed Methods Research. Los Angeles: Sage Publications.

Degn, Lise. 2015. "Sensemaking, Sensegiving and Strategic Management in Danish Higher Education." Higher Education 69(6): 901-913. https://doi.org/10.1007/s10734-014-9812-3.

Gioia, Dennis A., and James B. Thomas. 1996. "Identity, Image, and Issue Interpretation: Sensemaking during Strategic Change in Academia." Administrative Science Quarterly 41(3): 370-403.

Gioia, Dennis A., and Kumar Chittipeddi. 1991. "Sensemaking and Sensegiving in Strategic Change Initiation." Strategic Management Journal 12(6): 433-448. https://doi.org/10.1002/smj.4250120604.

Hayward, Fred M., and Razia Karim. 2019. "The Struggle for Higher Education Gender Equity Policy in Afghanistan: Obstacles, Challenges and Achievements." Education Policy Analysis Archives 27(139): 1 - 23. https://doi.org/10.14507/epaa.27.3036.

Ibrahimi, N. 2014. "Bureaucratic Policies and Patronage Politics: Prospect and Challenges of Private Higher Education in Afghanistan." Accessed November 11, 2019. http://www.afghanistan-analysts.org/wpcontent/uploads/2014/05/20140527-NIbrahimi-Private_Higher_Education.pdf.

Kapur, Devesh, and Megan Crowley. 2008. "Beyond the ABCs: Higher Education and Developing Countries." Center for Global Development, Working Paper 139. Washington DC: Center for Global Development. http://dx.doi.org/10.2139/ssrn.1099934 .

Kezar, Adrianna. 2013. "Understanding Sensemaking/Sensegiving in Transformational Change Processes from the Bottom Up." Higher Education 65(6): 761-780. https://doi.org/10.1007/s10734-012-9575-7.

Maitlis, Sally, and Thomas B. Lawrence. 2007. "Triggers and Enablers of Sensegiving in Organizations." Academy of Management Journal 50(1): 57-84. https://doi.org/10.5465/amj.2007.24160971.

Marshall, Catherine, and Gretchen B. Rossman. 2016. Designing Qualitative Research. Loss Angeles: Sage Publications.

McNernery, Frank. 2009. "Policy Options to Finance Public Higher Education in Afghanistan.” PhD. Diss., University of Massachusetts Amherst.

Ministry of Higher Education (MoHE). 2019. "Quality Assurance and Accreditation.” Accessed April 28, 2019. http://qaad.edu.af/en/resources/qaa-guidebook/.

Mussawy, Sayed Ahmad Javid, and Gretchen B. Rossman. 2018. "Quality Assurance and Accreditation in Afghanistan: Faculty Members' Perceptions from Selected Universities." Higher Learning Research Communications 8(2): 934. https://doi.org/10.18870/hlrc.v8i2.411.

Roof, David J. 2018. "Challenges and Opportunities: Community College Development in Afghanistan." In Handbook of Comparative Studies on Community Colleges and Global Counterparts, edited by Rosalind Latiner Raby and Edward J. Valeau, 1-15. Netherland: Springer International Publishing.

Roof, David J. 2015. "Day-By-Day: Higher Education in Afghanistan." FIRE: Forum for International Research in Education 1(3): 64-80. http://dx.doi.org/10.18275/fire201401031034. 
Rossman, Gretchen B., and Sharon F. Rallis. 2016. An Introduction to Qualitative Research: Learning in the Field. Thousand Oaks: Sage Publications.

Skolnik, Michael L. 2010. "Quality Assurance in Higher Education as a Political Process." Higher Education Management and Policy 22(1): 1-20. https://doi.org/10.1787/hemp-22-5kmlh5gs3zr0.

Srikanthan, Gitachari, and John F. Dalrymple. 2007. "A Conceptual Overview of a Holistic Model for Quality in Higher Education." International Journal of Educational Management 21(3): 173-193. https://doi.org/10.1108/09513540710738647.

Stensaker, Bjørn. 2007. "Quality as Fashion: Exploring the Translation of a Management Idea into Higher Education." In Quality Assurance in Higher Education: Trends in Regulation, Translation, and Transformation, edited by Don F. Westerheijden, Bjørn Stensaker, and Maria J. Rosa, 99-118. Netherlands: Springer.

Weick, Karl E. 1995. Sensemaking in Organizations. Thousand Oaks: Sage Publications.

Weick, Karl E., Kathleen M. Sutcliffe, and David Obstfeld. 2005. "Organizing and the Process of Sensemaking." Organization Science 16(4): 409-421. https://doi.org/10.1287/orsc.1050.0133.

Williams, James. 2016. "Quality Assurance and Quality Enhancement: Is There a Relationship?" Quality in Higher Education 22(2): 97-102. https://doi.org/10.1080/13538322.2016.1227207 